\title{
Biomasses Pyrolysis and Combustion Kinetics through n-th Order Parallel Reactions
}

\author{
Juan A. Conesa*, A. Domene \\ Chemical Engineering Department. University of Alicante. P.O. Box 99, 03080 Alicante \\ (Spain). Phone: +(34) 965903867 Fax: +(34) 965903826 \\ Author email address: ja.conesa@ua.es
}

\begin{abstract}
The decomposition of five different biomass samples was studied in a thermobalance. The samples consisted of esparto grass, straw, Posidonea Oceanic seaweed, waste from urban and agricultural pruning and waste of forest pruning. Both pyrolysis in inert atmosphere and combustion in the presence of oxygen were studied. Different heating rates were used and a global kinetic model, valid for all biomasses at the different conditions studied, was proposed. The kinetic model is able to fit all the runs performed with each biomass sample.
\end{abstract}

Keywords: pyrolysis, combustion, esparto grass, straw, seaweed, pruning waste, kinetics, thermogravimetry 


\section{INTRODUCTION}

The energy from the sun is stored in biomass through photosynthetic process. Photosynthesis starts with the capture of light by photosynthetic pigments accessories and conversion into electrical energy by the chlorophyll pigments of the reaction centers. In the next stage, not photochemical although light is required to activate certain enzymes, the stored chemical energy is used to reduce carbon dioxide and the resulting synthesis of carbohydrates.

In the process of thermochemical conversion of biomass is necessary to know the mechanisms by which thermal degradation occurs in the different molecular fractions that store chemical energy. The determination of kinetic parameters gives us information on the processes taking place as well as the structure and composition of the materials.

The determination of the kinetics corresponding to lignocellulosic materials involves the knowledge of the reaction mechanisms. However, the number of reactions that occur simultaneously in the most simple pyrolysis process is so great that it is practically impossible to develop a kinetic model that takes into account all these reactions. Thus, the pyrolysis is usually studied in terms of pseudo-mechanistic models. In these models, the products of pyrolysis are divided into char (non-volatile residue with a high carbon content), tars (mixtures of a great number of high molecular weight compounds that are volatile at the pyrolysis temperature but condense at room temperature) and gases (low molecular weight products which have a vapor pressure measurable at room temperature).

Lignocellulosic materials are formed by three different fractions, mainly: hemicellulose, cellulose and lignin. Thus, a critical question is whether the pyrolysis of a lignocellulosic material can be represented as the simple addition of its components or if these components interact chemically or physically, thereby causing the lignocellulosic material to behave in its own unique way during its thermal degradation. Studies of the kinetics of cellulose, hemicellulose and lignin separately have revealed that the interactions between fractions are important, and the pyrolysis behaviour of wood components is not completely additive. Besides, the separation process of the 
lignin, cellulose and hemicellulose may alter the structure of these compounds from their structure in the raw material. In particular, according to Evans et al[1], it is not possible to isolate lignin from wood without changing its structure, even using the same method it is difficult to obtain identical samples. However, in TG-DTG analysis of lignocellulosic material two or three peaks usually appear, that can be assigned to cellulose, lignin and hemicellulose, indicating that, although there are interactions between fractions, their identity is maintained.

The objective of this work is to study the thermal degradation products of five different biomass samples in order to establish a global kinetic model valid for the pyrolysis and combustion of all this variety of samples.

\section{MATERIALS AND METHODS}

In the study it was performed thermogravimetric analysis and determination of kinetic parameters of a series of biomass samples in both pyrolysis (He atmosphere) and combustion $\left(\mathrm{He} / \mathrm{O}_{2}=4: 1\right.$ atmosphere $)$.

Biomass samples under study represent biomass residues or Mediterranean endemic plants. Below are the studied species:

- EG: Esparto grass (Stipa tenacissima, L. or Macrochloa tenacissima, Kunth), Mediterranean grass with high PCI and easy regeneration.

- Straw (Straw Triticum, Hordeum, and Avena sativa), the main cereal crop residue.

- POS: Posidonea Oceanic seaweed.

- WUAP: Waste from urban and agricultural pruning. In the sampling of agricultural waste and garden clippings urban target species are those that represent $90 \%$ of the cultivated area of the counties with irrigated and rainfed land in the province of Alicante (Spain) and 85\% of susceptible ornamental pruning in the gardens of towns with more than 2000 inhabitants in the province of Alicante. Among the species they are Prunus Amygdalus, Citrus sinensis, Citrus limon, Prunus armeniaca and Olea europae as the major components. 
- WPF: Waste of pruning forest where they have chosen 5 sampling areas, all located in the province of Alicante. Among the species they are Pinus pinaster, Pinus nigra, Pinus halepensis, Cedrus deodara, Quercus Ilex and Juniperus phoenicea as the major components.

Table 1 presents the elemental analysis of the samples (carbon, hydrogen, nitrogen and sulfur) performed by oxidation of the sample to $1000{ }^{\circ} \mathrm{C}$ and subsequent detection of combustion products $\left(\mathrm{CO}_{2}, \mathrm{H}_{2} \mathrm{O}, \mathrm{N}_{2}\right.$ and $\left.\mathrm{SO}_{2}\right)$. The equipment used was a Perkin-Elmer 2400 (Perkin-Elmer, UK). Note that the amount of sulfur is neligible in all species but the Posidonea Oceanica, probably due to the presence of sulphur salts in the seawater (approx. 1-8\%).

The experiments consisted of six thermogravimetric analysis for each sample, carried out in two atmospheres of different reaction $\left(\mathrm{He}, \mathrm{He}: \mathrm{O}_{2}=4: 1\right)$ and three heating rates $(5,10$ and $20 \mathrm{~K} / \mathrm{min})$, using approx. $5 \mathrm{mg}$ sample. The total gas flow was 100 $\mathrm{mL} / \mathrm{min}$ and the temperature range studied from $25^{\circ} \mathrm{C}$ to $650^{\circ} \mathrm{C}$.

The experiments were repeated to check the reproducibility of the same, a fact which was verified by comparing the results of each series.

Analyses were performed by simultaneous TG-DTA equipment brand METTLER TOLEDO TGA/SDTA851e/LF/1600 model that can work between room temperature and $1600{ }^{\circ} \mathrm{C}$. On this equipment the specimen holder and the oven are arranged horizontally.

\section{RESULTS AND DISCUSSION}

Figures 1 to 5 present the thermal decomposition of the five studied species, both in pyrolysis and combustion at the three heating rates used. The results of the kinetic modeling are also in the Figure, but will be discussed later. In the Figures it can be seen both the effect of heating rate for the same process and for the species in question and the comparison the effect of heat and mass loss for different processes, pyrolysis and combustion.

[Figures 1 to 5] 
Each of the graphs shows the weight loss as the fraction $\mathrm{w}=\mathrm{m} / \mathrm{m}_{0}$ where $\mathrm{m}$ is the actual mass of the sample and $\mathrm{m}_{0}$ is the initial mass. Because biomass samples contain a residual amount of moisture (about 12\%) it is better to take as starting point of the analysis one in which the moisture had been lost.

The points represented, which have been those used for the kinetic analysis, have been selected according to techniques recommended by Caballero et al. [2] so that:

- The derivative of the points is calculated accurately and correctly.

- The points are equally spaced on a representation $\mathrm{dW} / \mathrm{dT}$ versus temperature.

- The fitting is simultaneous, with no variation of the kinetic constants, for at least three different heating rates.

Besides this, we use numerical techniques for solving differential equations and optimization methods prior definition of a proper objective function $[2,3]$.

\section{Effect of heating rate and reaction atmosphere}

In the previous graphs we can see the effect of the heating rate on TG curves. It can be appreciated that increasing heating rate curves are shifted to the right, i.e. that the weight losses occur at increasing temperatures. This behavior has been described by several researchers and can be explained using different arguments [4, 5]. Some authors argue that this behavior is due to changes in reaction mechanism caused by increased heating rate. Furthermore, poor heat transmission to the sample in the oven may cause increasing differences with increasing heating rate between the nominal and real temperature of the sample. It could also be due to different rates of heat dissipation or absorption of the reaction at different heating rate. However, the observed shift can be simply explained by the mathematical form of the kinetic laws $[4,6]$, which can provide a shift of the curves at higher temperatures with increasing reaction rate with the same kinetic constants.

Several authors have shown that some TG curves can be fitted to different kinetic models, providing very different values of the kinetic parameters, depending on the models used. Consequently, only models capable of explaining the shift in the TG 
with heating rate, without changing the kinetic parameters can be considered as potentially correct, however, if the heating rates which are very large works may be including heat transfer effects.

As for the effect of the atmosphere of reaction three different behaviors can be distinguished [7, 8]: pyrolysis + combustion of the residue formed (i.e., during the combustion process there is a first step of pyrolysis, followed by the reaction of oxygen with the residue of pyrolysis), oxidative pyrolysis (the combustion takes place in parallel to pyrolysis, being faster and taking place, therefore, at lower temperatures. In this process, oxygen reacts with the solid that is being decomposed before reaching the flame formation), and combustion delayed respect to the pyrolysis (the presence of oxygen produces partial oxygenation of solid material, causing the apparent delay in the decomposition of the solid).

Different amounts of final weight were obtained in the presence or absence of oxygen. Pyrolysis experiments reach smaller decomposition fractions (60-70\%) than experiments in the presence of oxygen, which gives a breakdown of $90 \%$ sample. In pyrolysis, the residue contains inorganic material and char, while in combustion, the residue is the ash formed by inorganic matter.

Note that in the processes of pyrolysis, the species EG, Straw and WUAP have decomposition about $70 \%$. In the case of POS is less than $60 \%$ in the best cases. This may be due to the presence of salts and inorganic substances deposited or adsorbed marine environment where this species occurs. These salts form a more refractory residue that increases the amount of pyrolytic residue.

The type of process that occurs in the samples studied in the present work depends on the biomass studied:

- For EG and POS there is a clear behavior of the type pyrolysis + combustion, since the first stages of decomposition in the presence of oxygen are crafty with the pyrolytic curves (in the absence of oxygen). At higher temperatures there is a clear decomposition of the residue formed in the first stages. 
- For WUAP and Straw, the behavior is similar but a slight acceleration of the combustion versus pyrolysis is observed.

- WFP shows a confusing behavior between pyrolysis+combustion and oxidative pyrolysis.

\section{Kinetic model for pyrolysis and combustion processes}

In the decomposition of biomass samples it can be distinguish three regions of weight loss [5, 9-11]. Due to this, the better results for the kinetic modeling will assume three different organic fractions that would decompose simultaneously in parallel reactions $[5,10,12]$. Each organic fraction would decompose into volatile and a carbonaceous solid residue.

Using this technique, pseudo reaction mechanisms are constructed, in which each reaction includes one or more elementary reactions, since gases and tars cannot be treated separately and are grouped as volatile matter. The kinetic parameters obtained are representative of each overall reaction.

The kinetic model proposed for the pyrolysis of biomasses could be interpreted considering the materials formed by three independent parts, each one following an independent reaction, as follows:

$$
\begin{aligned}
& \mathrm{w}_{\mathrm{s}_{10}} \text { Solid }_{1} \stackrel{1}{\longrightarrow}\left(\mathrm{w}_{\mathrm{s}_{10}}-\mathrm{v}_{1 \infty}\right) \text { Char }_{1}+\mathrm{v}_{1 \infty} \text { Volatiles }_{1} \\
& \mathrm{w}_{\mathrm{s}_{20}} \text { Solid }_{2} \stackrel{2}{\longrightarrow}\left(\mathrm{w}_{\mathrm{s}_{20}}-\mathrm{v}_{2 \infty}\right) \text { Char }_{2}+\mathrm{v}_{2 \infty} \text { Volatiles }_{2} \\
& \mathrm{w}_{\mathrm{s}_{30}} \text { Solid }_{3} \stackrel{3}{\longrightarrow}\left(\mathrm{w}_{\mathrm{s}_{30}}-\mathrm{v}_{3 \infty}\right) \text { Char }_{3}+\mathrm{v}_{3 \infty} \text { Volatiles }_{3}
\end{aligned}
$$

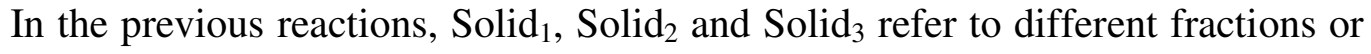
components of the original material, "Volatiles ${ }_{i}$ " are the gases and condensable volatiles evolved in the corresponding reactions ( $\mathrm{i}=1$ to 3 ), and "Char," is the char formed in the decomposition of each $\operatorname{Solid}_{\mathrm{i}}(\mathrm{i}=1$ to 3 ). On the other hand, the small letters represent the yield coefficients representative of each reaction and consequently, it is considered not to be changing with time and with the extension of the reaction. Moreover, each fraction has a yield coefficient that represents the maximum mass fractions obtainable by each reaction. In this way, $v_{i \infty}$ is the yield coefficient for the Volatiles $s_{i}$ and $v_{i}$ is the 
mass fraction of volatiles. The different initial mass fraction of the components $\left(\mathrm{w}_{\text {sio }}\right)$ are related so the following must be fulfilled:

$$
\sum_{i=1}^{3} w_{s_{i 0}}=1
$$

Considering an $n$-th order kinetic decomposition, the kinetic equations for the pyrolysis runs can be expressed as followed:

$-\frac{d w_{s_{i}}}{d t}=k_{i} w_{s_{i}}^{n_{i}}$

or

$\frac{d V_{i}}{d t}=k_{i}\left(V_{i \infty}-V_{i}\right)^{n_{i}}$

with the kinetic constants following the Arrhenius equation:

$$
\mathrm{k}_{\mathrm{i}}=\mathrm{k}_{\mathrm{i} 0} \exp \left(-\frac{\mathrm{E}_{\mathrm{i}}}{\mathrm{RT}}\right) \quad \mathrm{i}=1 \text { to } 3
$$

In the equations, $V_{i}$ and $V_{i \infty}$ represent the volatiles evolved from the decomposition of each fraction, and the maximum yield of volatiles that can be obtained, respectively.

The calculated values were obtained by integration of the differential equations presented in the kinetic model, by the explicite Euler method, but considering and testing that the intervals of time are small enough so the errors introduced are negligible. The optimization method of the function Solver in a Microsoft Excel spreadsheet was used to minimize the differences between experimental and calculated weight loss and their derivatives. The objective function $(\mathrm{OF})$ to minimize was the sum of the square differences between experimental and calculated weight loss values:

$$
O . F .=\sum_{j} \sum_{i}\left[w_{\exp _{i j}}-w_{c a l c_{i j}}\right]^{2}
$$

where ' $i$ ' represents the experimental data at time ' $t$ ' in the experiment with a heating rate 'j'. The value of $w_{\text {expij }}$ or $w_{\text {calij }}$ represents the weight loss fraction in the experimental and calculated data, respectively. 
On the other hand, the model proposed to explain the thermal decomposition of biomasses in the presence of oxygen is the same that has been considered in the case of pyrolysis runs, but with different values of some kinetic constants. For all the fractions (1 to 3 ), the same values of apparent activation energy and reaction order obtained under a helium atmosphere have been considered, but the pre-exponential factor is assumed to be different due to the presence of the oxygen. This type of model satisfactorily fitted the decomposition of other materials [13, 14]. With all these considerations, acceptable correlations of the data are obtained.

In order to obtain a single set of parameters for the combustion of the material, all the runs at the different heating rates were correlated with the same set of parameters. For the optimization of each of the biomasses studied, 6 TG runs (approx. 600 experimental points) are correlated and 14 parameters were obtained $\left(3 \times E_{i}, 3 \mathrm{x} \mathrm{n}_{\mathrm{i}}\right.$, $3 \mathrm{x}_{\mathrm{i} 0}$ in pyrolytic conditions, $3 \mathrm{x}_{\mathrm{i} 0}$ in combustion conditions and $2 \mathrm{x}_{\mathrm{i} 0}$ ). The kinetic parameters for decomposition of each fraction in oxidative and pyrolytic conditions are shown in Table 1.

\section{[Table 1]}

Figures 1 to 5 shows the loss curves of experimental and calculated weight loss, at all heating rates studied and both in inert and oxidative atmosphere. It is clear that best fits would be obtained if all parameters are allowed to vary for each run, but they would be less representative of the overall process.

Figure 6 shows the calculated evolution of each of the fractions considered in the pyrolysis and combustion of WFP at $5{ }^{\circ} \mathrm{C} / \mathrm{min}$. The remaining biomass samples present a similar behavior. From this figure it can be concluded that:

- "Fraction 2" begins to decompose slightly before "Fraction 1".

- "Fraction 2" is the more contributing to the total weight loss of all biomass samples studied.

- The decomposition of "Fraction 1" is accelerated in the presence of oxygen, but the form of the curve remains. The contrary is true for "Fraction 2", that is almost unaffected by the presence of oxygen. 
- "Fraction 3" decomposes in a wider temperature range. It is the fraction presenting more differences comparing combustion and pyrolysis.

Comparing these observations with the literature it is clear that "Fraction 1" corresponds to the cellulosic materials. It decomposes in a temperature range 300-400 ${ }^{\circ} \mathrm{C}$ for pyrolysis and goes to $500{ }^{\circ} \mathrm{C}$ for higher heating rates. This is due to the main reactions that consist in breaking down the glicosidic bonds with the subsequent partial depolimerization of the cellulosic material of the wood. To this fraction corresponds activation energies between $150-250 \mathrm{~kJ} / \mathrm{mol}$. The decomposition of this fraction is very much accelerated in the presence of oxygen. The ratios between $\left(\mathrm{k}_{\mathrm{io}}\right)_{\text {pyrolysis }}$ with the corresponding $\left(\mathrm{k}_{\mathrm{io}}\right)_{\text {combustion }}$ (data in Table 2), are in the range $10^{3}-10^{6}$, whereas for the other fractions this ratio is $1-10$.

On the other hand, "Fraction 2" should correspond to hemicelluloses. It decomposes in the temperature range $200-250{ }^{\circ} \mathrm{C}$ in combustion and $250-300{ }^{\circ} \mathrm{C}$ in pyrolysis conditions. This corresponds to activation energies between 100 and 300 $\mathrm{kJ} / \mathrm{mol}$, depending on the biomass sample. It is observed a great difference in this kinetic parameter, indicating that the decomposition of this fraction is given with different energetic requirements for the different biomasses.

"Fraction 3" corresponds to the ligninic material of the biomass. It is the most refractory and difficult to thermally decompose. Lignin is the chemical constituent of wood that holds the greatest influence on its physical and chemical characteristics. The higher percentage of fixed carbon is present in woods with the higher percentages of lignin. This is attributed to the fact that the lignin is the most resistant to the thermal decomposition when comparing to the cellulose and hemicellulose, due to its complex structure. The ligninic fraction decomposes between 300 and $500{ }^{\circ} \mathrm{C}$ in the combustion conditions, but pyrolysis takes place at higher temperatures. The orders of reaction are the highest found, accordingly to literature $[6,15,16]$. The activation energies vary in the range $100-230 \mathrm{~kJ} / \mathrm{mol}$.

The reaction of decomposition of lignin and thus the formation of volatile is more favoured in the presence of oxygen, due to its diffusion inside the sample producing several reactions. These reactions favour the production of volatile species and a higher thermal degradation. Moreover, the decomposition of lignin in POS and 
WUAP present very significant differences compared to other species probably due to the structure and reactivity of their lignin vs oxygen reaction [16].

\section{CONCLUSIONS}

The decomposition of five different biomass samples was studied in a thermobalance. Both pyrolysis in inert atmosphere and combustion in the presence of oxygen were studied. Different heating rates were used and a global kinetic model, valid for all biomasses at the different conditions studied, was proposed. The kinetic model is able to fit all the runs performed with each biomass sample. Kinetic parameters have been calculated for thermal decomposition of studied samples.

\section{ACKNOWLEDGEMENTS}

Authors acknowledge the financial support for this work provided by PROMETEO/2009/043/FEDER and ACOMP2010/075 of Generalitat Valenciana (Spain) and CTQ2008-05520 (Spanish MCI).

\section{REFERENCES}

[1] R.J. Evans, T.A. Milne, M.N. Soltys, Direct mass-spectrometric studies of the pyrolysis of carbonaceous fuels. III. Primary pyrolysis of lignin, Journal of Analytical and Applied Pyrolysis, 9 (1986) 207-236.

[2] J.A. Caballero, J.A. Conesa, Mathematical considerations for nonisothermal kinetics in thermal decomposition, Journal of Analytical and Applied Pyrolysis, 73 (2005) 85-100.

[3] G. Várhegyi, P. Szabó, E. Jakab, F. Till, Least squares criteria for the kinetic evaluation of thermoanalytical experiments. Examples from a char reactivity study, Journal of Analytical and Applied Pyrolysis, 57 (2001) 203-222.

[4] J.A. Conesa, J.A. Caballero, A. Marcilla, R. Font, Analysis of different kinetic models in the dynamic pyrolysis of cellulose, Thermochimica Acta, 254 (1995) 175192.

[5] J.A. Caballero, J.A. Conesa, R. Font, A. Marcilla, Pyrolysis kinetics of almond shells and olive stones considering their organic fractions, Journal of Analytical and Applied Pyrolysis, 42 (1997) 159-175.

[6] J.A. Caballero, R. Font, A. Marcilla, J.A. Conesa, New kinetic model for thermal decomposition of heterogeneous materials, Industrial and Engineering Chemistry Research, 34 (1995) 806-812. 
[7] R. Font, A. Fullana, J. Conesa, Kinetic models for the pyrolysis and combustion of two types of sewage sludge, Journal of Analytical and Applied Pyrolysis, 74 (2005) 429-438.

[8] J.A. Conesa, R. Font, A. Fullana, J.A. Caballero, Kinetic model for the combustion of tyre wastes, Fuel, 77 (1998) 1469-1475.

[9] J.A. Conesa, A. Marcilla, J.A. Caballero, Evolution of gases from the pyrolysis of modified almond shells: Effect of impregnation with $\mathrm{CoCl} 2$, Journal of Analytical and Applied Pyrolysis, 43 (1997) 59-69.

[10] G. Várhegyi, H. Chen, S. Godoy, Thermal decomposition of wheat, oat, barley, and brassica carinata straws. a kinetic study, Energy Fuels, 23 (2009) 646-652.

[11] G. Várhegyi, Z. Czégény, E. Jakab, K. McAdam, C. Liu, Tobacco pyrolysis. Kinetic evaluation of thermogravimetric-mass spectrometric experiments, Journal of Analytical and Applied Pyrolysis, 86 (2009) 310-322.

[12] G. Várhegyi, M.J. Antal Jr, E. Jakab, P. Szabó, Kinetic modeling of biomass pyrolysis, Journal of Analytical and Applied Pyrolysis, 42 (1997) 73-87.

[13] I. Aracil, R. Font, J.A. Conesa, A. Fullana, TG-MS analysis of the thermooxidative decomposition of polychloroprene, Journal of Analytical and Applied Pyrolysis, 79 (2007) 327-336.

[14] J.A. Conesa, J. Moltó, R. Font, S. Egea, Polyvinyl chloride and halogen-free electric wires thermal decomposition, Industrial and Engineering Chemistry Research, 49 (2010) 11841-11847.

[15] A.G. Barneto, J.A. Carmona, J.A. Conesa Ferrer, M.J. DÃ-az Blanco, Kinetic study on the thermal degradation of a biomass and its compost: Composting effect on hydrogen production, Fuel, (2009).

[16] T. Cordero, PREPARACIÓN Y CARACTERIZACIÓN DE MATERIALES CARBONOSOS PARA

LA ELIMINACIÓN DE CONTAMINANTES GASEOSOS, in, Malaga, 1987. 


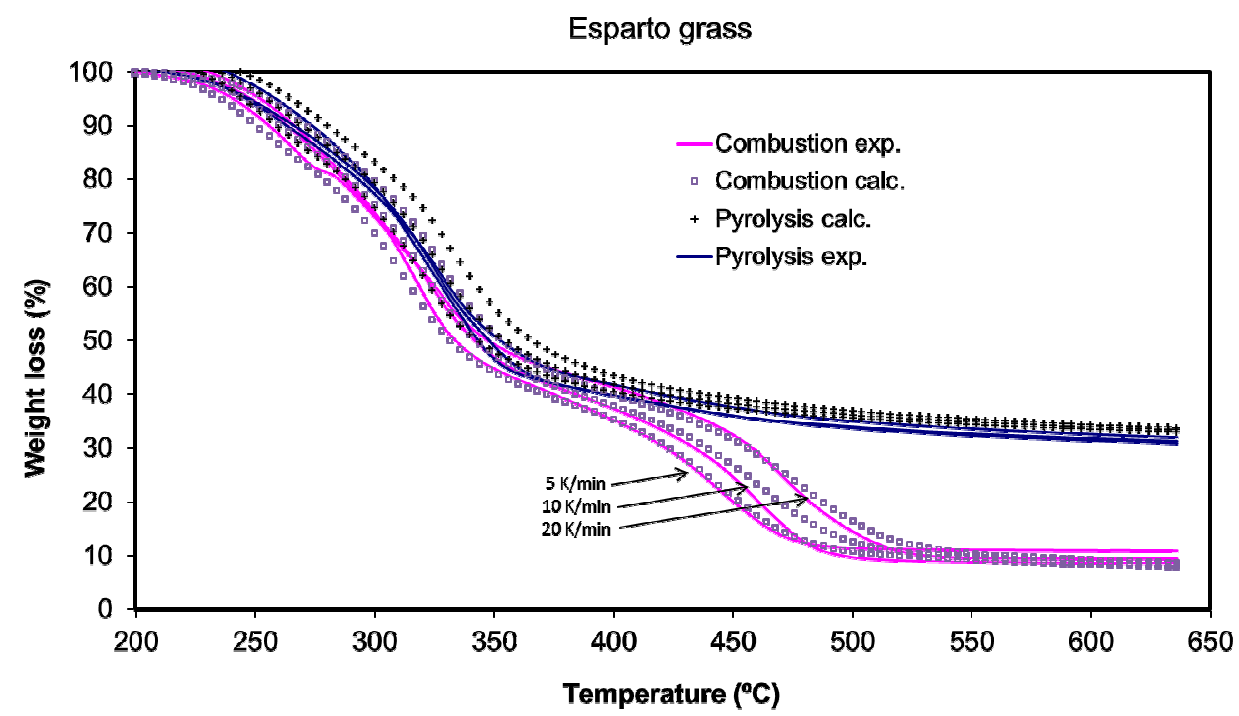

Figure 1.

Pyrolysis and combustion of Esparto grass at the different heating rates. Experimental curve and calculated points.

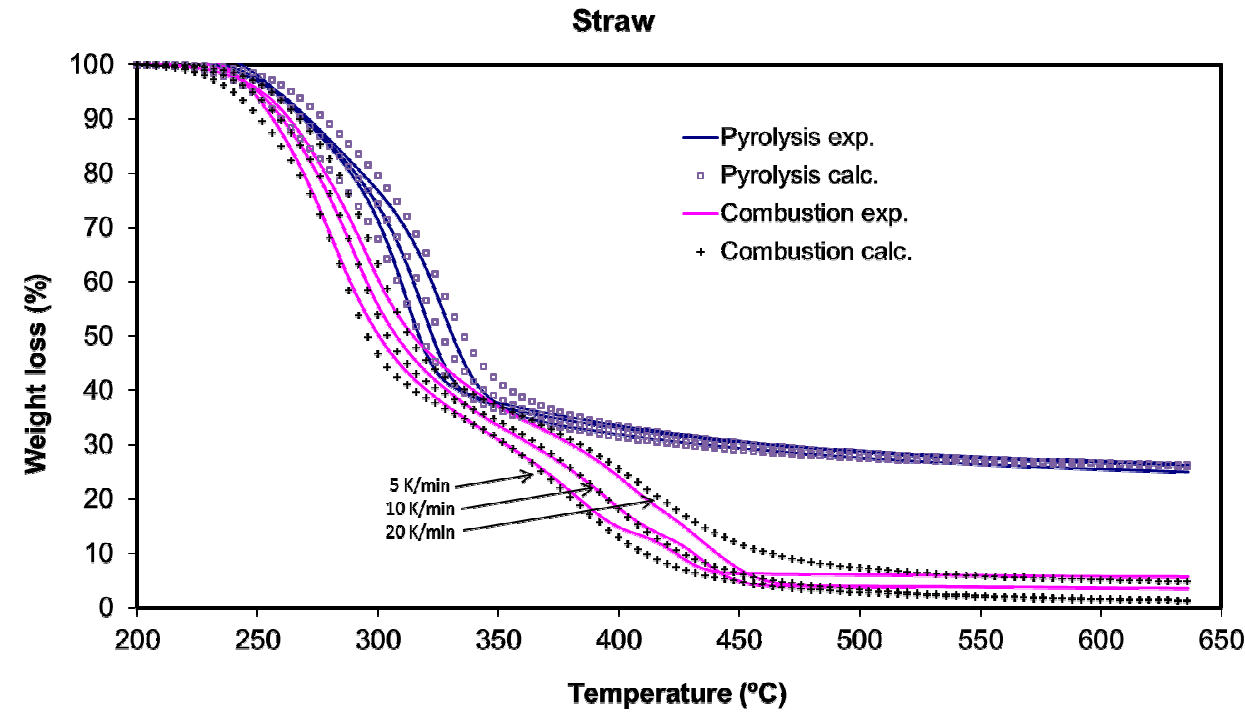

Figure 2.

Pyrolysis and combustion of Straw at the different heating rates. Experimental curve and calculated points. 


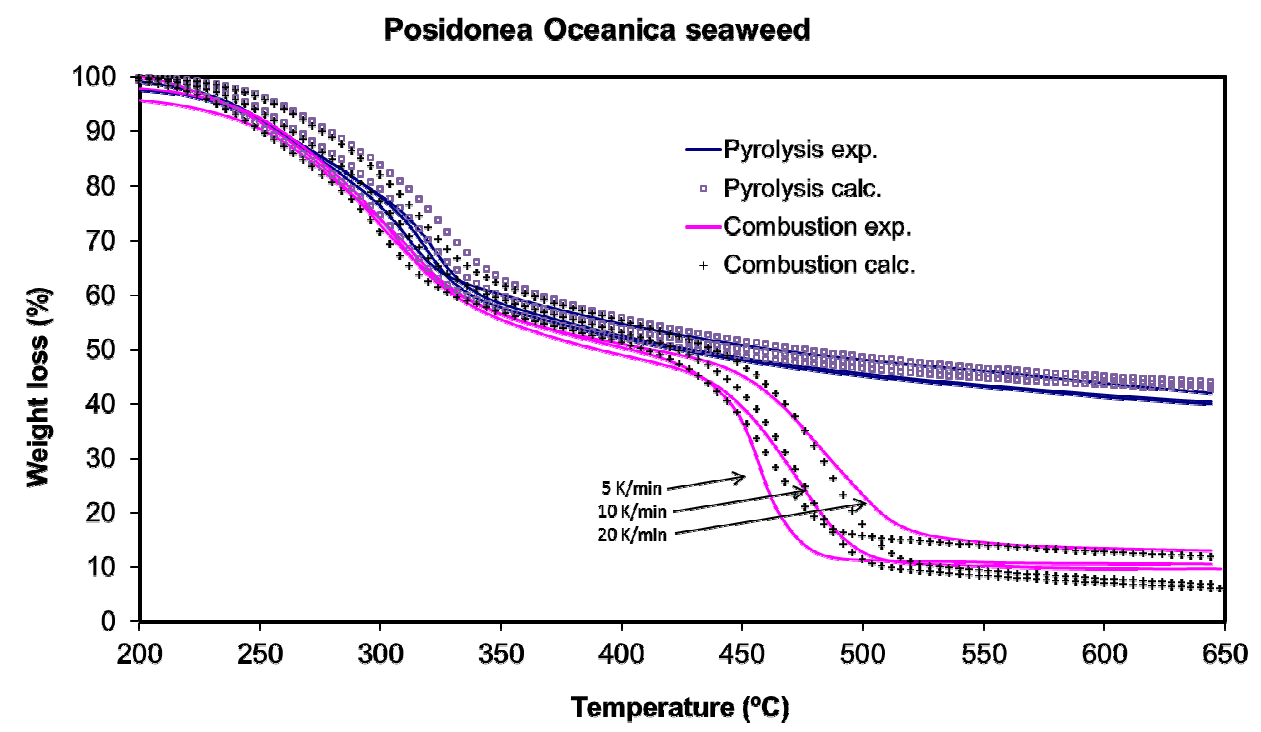

Figure 3.

Pyrolysis and combustion of Posidonea Oceanica seaweed at the different heating rates. Experimental curve and calculated points.

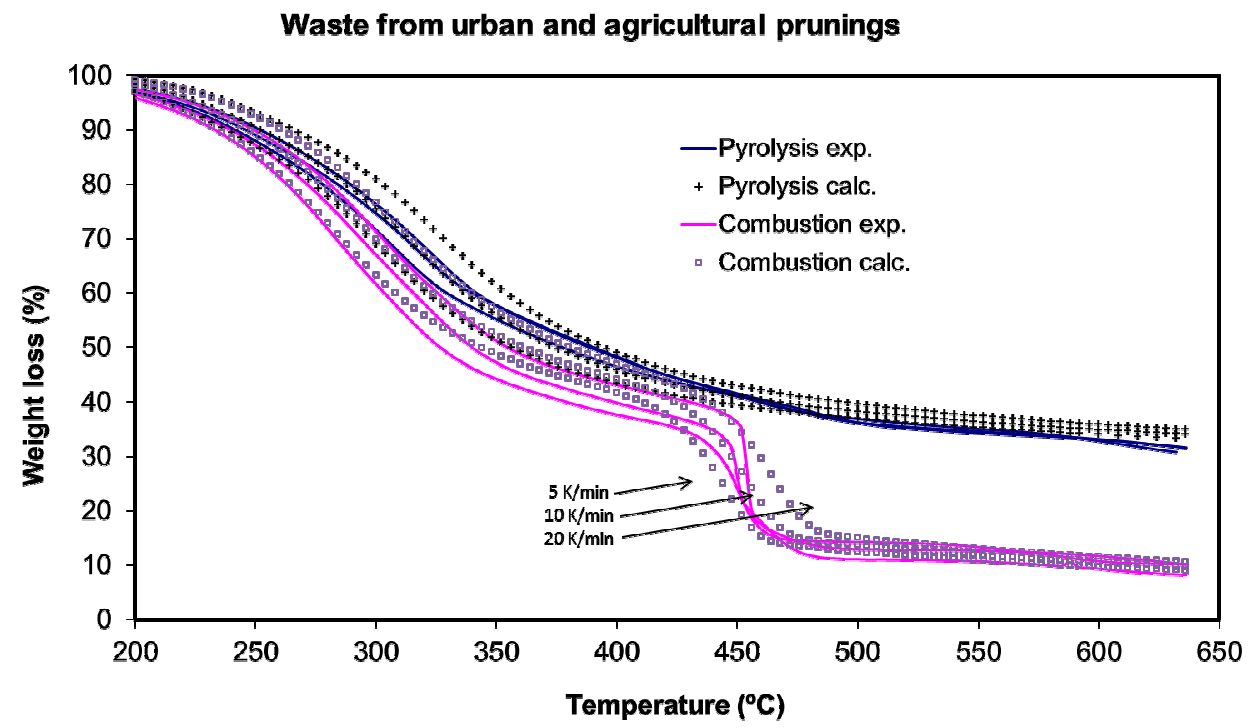

Figure 4.

Pyrolysis and combustion of agricultural and urban pruning wastes at the different heating rates. Experimental curve and calculated points. 


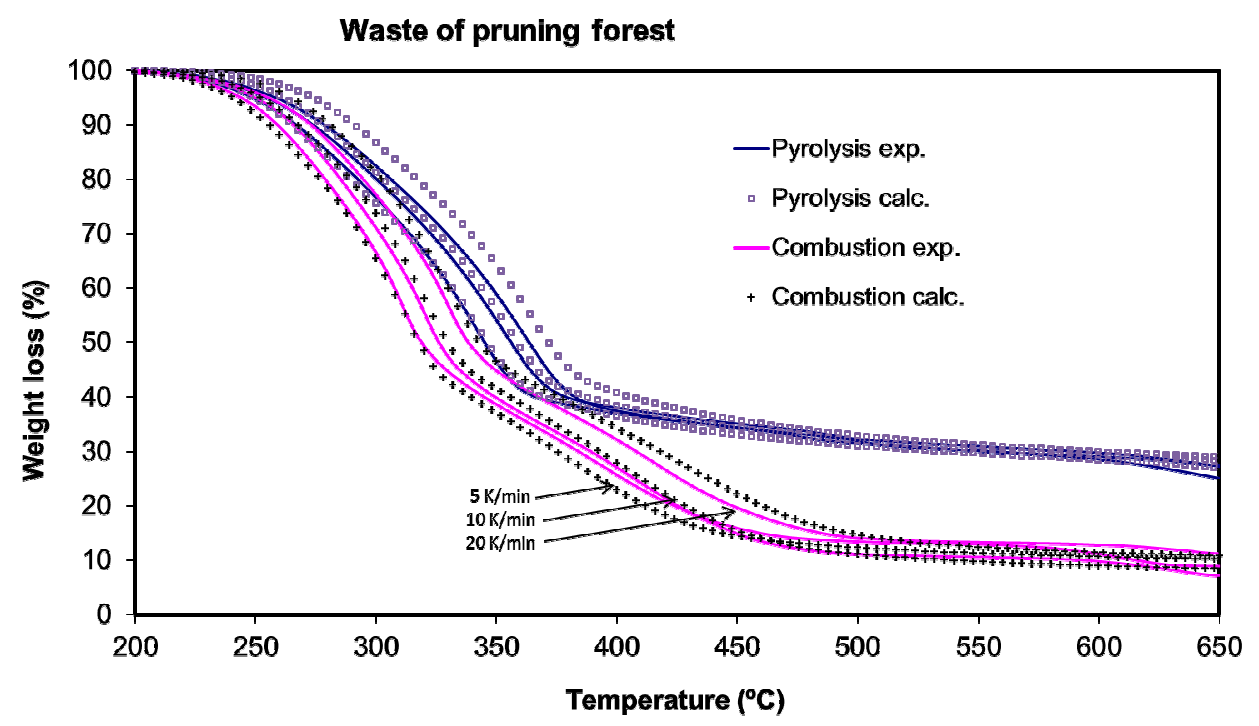

Figure 5.

Pyrolysis and combustion of waste from forest pruning at the different heating rates. Experimental curve and calculated points.

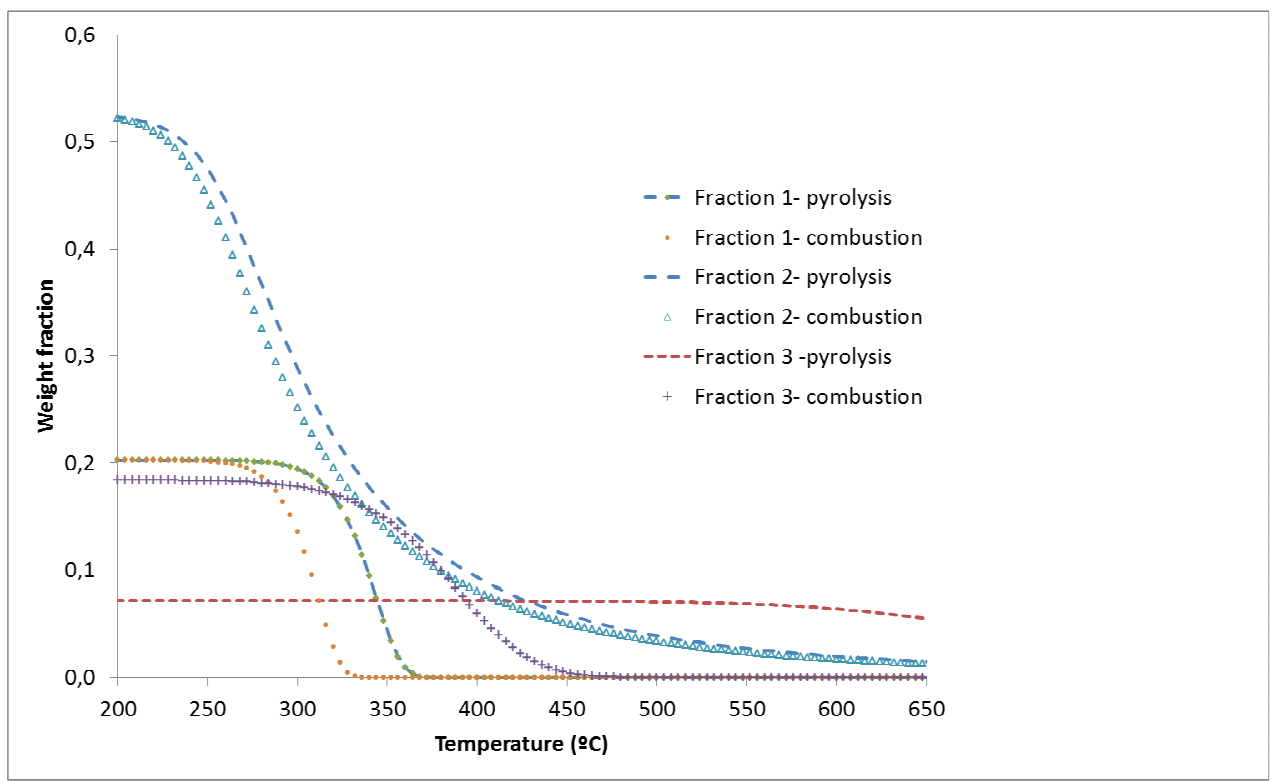

Figure 6.

Evolution of the different fraction during the pyrolysis and combustion of waste from forest pruning at $5^{\circ} \mathrm{C} / \mathrm{min}$. 
Table 1. Elemental analysis of the biomass samples (\% dry wt.)

\begin{tabular}{|c|c|c|c|c|c|}
\hline & Esparto grass & Straw & Posidonea Oc. & $\begin{array}{c}\text { Agric. Urban } \\
\text { pruning waste }\end{array}$ & $\begin{array}{c}\text { Forest pruning } \\
\text { waste }\end{array}$ \\
\hline N & 0.50 & 0.21 & 0.71 & 2.09 & 0.65 \\
\hline C & 38.16 & 42.93 & 34.85 & 48.06 & 40.12 \\
\hline H & 5.40 & 6.16 & 4.54 & 5.81 & 5.44 \\
\hline S & 0.00 & 0.00 & 0.62 & 0.00 & 0.00 \\
\hline O & 55.94 & 50.70 & 59.28 & 44.04 & 53.79 \\
\hline
\end{tabular}

Table 2. Kinetic parameters obtained in the pyrolysis and combustion fitting.

\begin{tabular}{|c|c|c|c|c|c|}
\hline & $\begin{array}{l}\text { Esparto } \\
\text { grass }\end{array}$ & Straw & $\begin{array}{c}\text { Posidonea } \\
\text { Oceanica }\end{array}$ & $\begin{array}{l}\text { Agric. } \\
\text { Urban } \\
\text { pruning } \\
\text { waste }\end{array}$ & $\begin{array}{c}\text { Forest } \\
\text { pruning } \\
\text { waste }\end{array}$ \\
\hline $\mathrm{E}_{1}(\mathrm{~kJ} / \mathrm{mol})$ & 171.75 & 162.13 & 211.25 & 295.92 & 103.21 \\
\hline $\mathrm{E}_{2}(\mathrm{~kJ} / \mathrm{mol})$ & 150.37 & 239.63 & 255.98 & 130.56 & 199.37 \\
\hline $\mathrm{E}_{3}(\mathrm{~kJ} / \mathrm{mol})$ & 229.26 & 181.63 & 143.48 & 102.48 & 125.86 \\
\hline $\mathrm{n}_{1}$ & 1.37 & 1.93 & 1.00 & 1.15 & 1.27 \\
\hline $\mathrm{n}_{2}$ & 7.06 & 178 & 2.12 & 2.90 & 1.17 \\
\hline $\mathrm{n}_{3}$ & 2.49 & 6.31 & 9.21 & 9.48 & 4.66 \\
\hline $\mathbf{w}_{20}$ & 0.468 & 0.452 & 0.503 & 0.443 & 0.525 \\
\hline $\mathbf{w}_{30}$ & 0.257 & 0.301 & 0.125 & 0.314 & 0.202 \\
\hline $\begin{array}{l}\mathrm{k}_{\mathrm{o1}}\left(\mathrm{min}^{-1}\right) \\
\text { pyrolysis }\end{array}$ & $1,40 \mathrm{E}+05$ & $3,03 \mathrm{E}+05$ & $1,36 \mathrm{E}+06$ & $3,29 \mathrm{E}+09$ & $3,35 \mathrm{E}+04$ \\
\hline $\begin{array}{c}\mathrm{k}_{02}\left(\mathrm{~min}^{-1}\right) \\
\text { pyrolysis }\end{array}$ & $1,69 \mathrm{E}+16$ & $3,05 \mathrm{E}+21$ & $3,49 \mathrm{E}+23$ & $1,44 \mathrm{E}+12$ & $3,66 \mathrm{E}+16$ \\
\hline $\begin{array}{c}\mathbf{k}_{\mathrm{o} 3}\left(\mathrm{~min}^{-1}\right) \\
\text { pyrolysis }\end{array}$ & $5,47 \mathrm{E}+20$ & $8,45 \mathrm{E}+18$ & $9,39 \mathrm{E}+15$ & $5,59 \mathrm{E}+12$ & $1,56 \mathrm{E}+12$ \\
\hline $\begin{array}{c}\mathrm{k}_{\mathrm{o1}}\left(\mathrm{min}^{-1}\right) \\
\text { combustion }\end{array}$ & $1,07 \mathrm{E}+09$ & $7,34 \mathrm{E}+12$ & $2,84 \mathrm{E}+09$ & $1,58 \mathrm{E}+14$ & $3,14 \mathrm{E}+07$ \\
\hline $\begin{array}{l}\mathrm{k}_{02}\left(\mathrm{~min}^{-1}\right) \\
\text { combustion }\end{array}$ & $1,83 \mathrm{E}+16$ & $3,08 \mathrm{E}+22$ & $7,14 \mathrm{E}+23$ & $3,36 \mathrm{E}+12$ & $3,49 \mathrm{E}+17$ \\
\hline $\begin{array}{l}\mathrm{k}_{\mathrm{o} 3}\left(\mathrm{~min}^{-1}\right) \\
\text { combustion }\end{array}$ & $8,60 \mathrm{E}+20$ & $1,61 \mathrm{E}+19$ & $1,09 \mathrm{E}+16$ & $5,97 \mathrm{E}+12$ & $2,64 \mathrm{E}+12$ \\
\hline
\end{tabular}

